\title{
Impact of Combination of EGR, SCR, and DPF Technologies for the Low-Emission Rail Diesel Engines
}

\author{
Athanasios G. Konstandopoulos ${ }^{1,2}$ - Margaritis Kostoglou ${ }^{1,3}$ - Carlo Beatrice $^{4}$. \\ Gabriele Di Blasio $^{4}$ • Abdurrahman Imren ${ }^{5}$ - Ingemar Denbratt ${ }^{5}$
}

Received: 13 June 2015 / Revised: 16 June 2015 / Accepted: 17 June 2015 / Published online: 3 July 2015

(C) Springer SIP, AG 2015

\begin{abstract}
The EU emission standards for new rail diesel engines are becoming more stringent: stage IV emission targets have just come into effect, while stage $\mathrm{V}$ is in under considerations. Both exhaust gas recirculation (EGR) and selective catalytic reduction (SCR) technologies can be used to reduce nitric oxide (NOx) emissions, while the PM emission control requires a diesel particulate filter (DPF). The use of SCR requires on-board storage of urea, while the use of DPF needs to take into account its impact on engine efficiency performance. Both of these technologies require specific studies when applied to the rail engines; in particular, it becomes necessary to evaluate the engine performance trade-offs in order to evaluate how these technologies can be utilized efficiently in rail applications in order to meet current and future emission standards. The present study assesses the application of these technologies in diesel railcars on a quantitative basis using oneand three-dimensional numerical simulation tools. In particular, the study considers a $560-\mathrm{kW}$ railcar engine with the use of different technology combinations for NOx reduction: SCR or
\end{abstract}

Athanasios G. Konstandopoulos

agk@cperi.certh.gr

1 Aerosol and Particle Technology Laboratory (APTL), Chemical Process Engineering Research Institute (CPERI), Centre for Research and Technology Hellas (CERTH), 6th km, Charilaou-Thermi Road, Thermi 57001 Thessaloniki, Greece

2 Department of Chemical Engineering, Aristotle University of Thessaloniki, PO. Box 1517, 54006 Thessaloniki, Greece

3 Department of Chemistry, Aristotle University of Thessaloniki, Univ. Box 116, 54124 Thessaloniki, Greece

4 CNR-IM, Istituto Motori, Via G. Marconi 4, 80125 Naples, Italy

5 Applied Mechanics, Chalmers University of Technology, 41296 Gothenburg, Sweden
$\mathrm{EGR}+\mathrm{DPF}$, and $\mathrm{EGR}+\mathrm{DPF}+\mathrm{SCR}$. The NOx and PM emission performances are evaluated over the $\mathrm{C} 1$ homologation cycle and, in the case of the DPF, over an approximated railcar driving cycle as well. Several BSNOx targets were considered: $2 \mathrm{~g} / \mathrm{kWh}, 1 \mathrm{~g} / \mathrm{kWh}$, and $0.4 \mathrm{~g} / \mathrm{kWh}$. Simulation results indicate that EGR + DPF + SCR-based solution is necessary to achieve stage IV emission limits for the 560$\mathrm{kW}$ engine. On the other hand, SCR-based solutions have the potential to go beyond the stage IV NOx limit through scaling up the size of the SCR device and the on-board urea storage.

Keyword Particulate emissions · NOx emissions · Exhaust gas recirculation $\cdot$ Selective catalytic reduction $\cdot$ Diesel particulate filter

\section{Nomenclature}

ABDC After bottom dead center

ATDC After top dead center

BBDC Before bottom dead center

BSFC Brake-specific fuel consumption

BSNOx Brake-specific nitrogen oxides

BSUC Brake-specific urea consumption

BTDC Before top dead center

CAC Charge air cooler

CA crank angle

CB Constant boost

CDPF Catalyzed diesel particulate filter

CFD Computational fluid dynamics

CL Constant lambda

$\mathrm{CO}_{2} \quad$ Carbon dioxide

Cpsi Cells per square inch

CR Common rail DI direct injection

DIJet Name of commercial combustion model software 


$\begin{array}{ll}\text { DOC } & \text { Diesel oxidation catalyst } \\ \text { DPF } & \text { diesel particulate filter } \\ \text { EEA } & \text { European Environmental Agency } \\ \text { EGR } & \text { Exhaust gas recirculation } \\ \text { EVC } & \text { Exhaust valve closure } \\ \text { EVO } & \text { Exhaust valve opening } \\ \text { HACA } & \text { Hydrogen abstraction acetylene addition } \\ \text { HC } & \text { Hydrocarbon emissions } \\ \text { HD } & \text { Heavy duty } \\ \text { HPEGR } & \text { High-pressure loop EGR } \\ \text { HR } & \text { Heat release } \\ \text { HRR } & \text { Heat release rate } \\ \text { IP } & \text { Injection pressure } \\ \text { IVC } & \text { Inlet valve closure } \\ \text { IVO } & \text { Inlet valve opening } \\ \text { KH } & \text { RT Kelvin-Helmholtz/Rayleigh-Taylor } \\ \text { LD } & \text { light duty } \\ \text { MBF } & \text { Mass burned fraction } \\ \text { MFR } & \text { Mass flow rate } \\ \text { NOx } & \text { Nitric oxides } \\ \text { ODE } & \text { Ordinary differential equation } \\ \text { OFA } & \text { Open frontal area of monolith } \\ \text { Pback } & \text { Exhaust backpressure } \\ \text { PCCI } & \text { Premixed charge compression ignition } \\ \text { pfp } & \text { Peak firing pressure } \\ \text { PM } & \text { Particulate matter } \\ \text { PSR } & \text { Perfectly stirred reactor } \\ \text { PaSR } & \text { Partially stirred reactor } \\ \text { RNG } & \text { Renormalization group } \\ \text { SCR } & \text { Selective catalytic reduction } \\ \text { SOC } & \text { Soot oxidation catalyst } \\ \text { SOF } & \text { Solid organic fraction (fraction of total HC that is } \\ & \text { adsorbed on the PM) } \\ \text { SOI } & \text { Start of injection } \\ \text { TC } & \text { Turbocharger } \\ \text { vppm } & \text { Volumetric parts per million } \\ \text { WG } & \text { Waste gate } \\ & \end{array}$

\section{Introduction}

The application of the EU Non-Road Mobile Machinery (NRMM) Directive to rail diesel vehicles, and in particular, the application of the stage IV emission standards, raises significant challenges in terms of vehicle design, reliability, and life cycle cost. Simultaneously, a new regulation for railcars named stage $\mathrm{V}$ has been proposed. Table 1 shows the emission targets for the past, current, and proposed regulations [2].

According to the European Environment Agency (EEA), nitric oxide (NOx) and particulate matter (PM) emissions from the rail sector account for only $1-1.5 \%$ of the total emissions from all transport sectors [3]. Furthermore, compared to the road transport sector, fuel consumption (FC)
Table 1 Evolution of the emission standards for non-road diesel engines in the power range $130-560 \mathrm{~kW}$

\begin{tabular}{lllllll}
\hline Stage & Date & \multicolumn{5}{l}{ Emissions $(\mathrm{g} / \mathrm{kWh})$} \\
\cline { 3 - 7 } & & $\mathrm{CO}$ & $\mathrm{HC}$ & $\mathrm{NOx}$ & $\mathrm{PM}$ & $\mathrm{PN}$ \\
\hline IIIB & 01.2011 & 3.5 & 0.19 & 2 & 0.025 & - \\
IV & 01.2014 & 3.5 & 0.19 & 0.4 & 0.025 & - \\
V & 2021 & 3.50 & 0.19 & 2.00 & 0.015 & $1 \times 10^{12}$ \\
\hline
\end{tabular}

For stage $\mathrm{V}$, a limit on the particle number $(\mathrm{PN})$ emission is proposed [1]

and $\mathrm{CO}_{2}$ emissions are lower in the rail sector due to the lower rolling resistance of rail vehicles and the higher passenger densities achieved. Therefore, in order to avoid the risk of a partial modal shift from rail transport to a less-sustainable mode such as road transport, it is necessary to investigate the impacts of the NRMM Directive and stage IV emission limits on the rail vehicle design, reliability, and life cycle cost and, among others, to investigate the adaption of state-of-the-art emission control technologies in the road sector to diesel railcars.

The use of on-road diesel exhaust after-treatment technologies for heavy-duty (HD) trucks in railcars is a logical step, having comparable engine technologies. However, while investigating their impact on engine performance and emissions, the on-board space requirements have to be accurately evaluated, as well. In particular, the onboard space saving is one of the main key points for the vehicle designers. Moreover, it would be unreasonable to assume a priori that such technologies could be directly transferred to higher-power rail diesel applications such as heavy haul locomotives. Therefore, aim of the present paper is to address this knowledge gap since no such study related to rail vehicles evaluating the different emission control options exists in the literature.

Specifically, this study aims to investigate the trade-off between NOx and PM emissions, on the one hand, and fuel and urea consumption, on the other, that is likely to arise from the use of exhaust gas recirculation (EGR), diesel particulate filter (DPF) and selective catalytic reduction (SCR) technologies in diesel railcars. Indeed, the trade-offs regarding PM emissions, FC, and urea consumption need to be addressed for optimum application of these technologies to railcars. Such technologies have already been deployed successfully in the field for on-road vehicles and naturally attract the interest of the rail industry for potential application [1]. In particular, the present study considers a $560-\mathrm{kW}$ diesel engine for railcar applications since this application area covers high-powered railcars $(390-650 \mathrm{~kW})$ which represent about $24 \%$ of the installed power in the fleet, most of which is operated in the UK. First, the impacts on emissions and FC have been analyzed separately for EGR + DPF and SCR. Then, their combination has been evaluated with respect the two separate configurations. 
The presented study is one of the results of a project carried out within the Seventh European Framework program entitled "Clean European Rail-Diesel" (Cleaner-D) in which several academic and industrial partners have participated [4].

The design and performance analysis has been carried out using numerical simulation tools (GT-Power and KIVA 4 computational fluid dynamic (CFD) codes). Simulation results indicate that stage IV emission targets, in terms of PM and NOx, can be achieved by using the analyzed technologies, and their impact on engine is mandatory in order to find the best solution for FC saving, on-board space, and vehicle weight. The methodology of the study and simulation results are described in the following.

\section{Engine Characteristics and Emission Test Cycle}

The characteristics of the engine model considered are based on the available engine specifications in the field of HD rail engines. Specifically, a V8, 20-L Turbocharged diesel engine was selected as a reference in terms of geometry (bore, stroke, cylinder number and arrangement, etc.) and engine output data (power, efficiency, etc.). Experimental data of this representative engine were provided by the industrial partner of the Cleaner-D consortium and shared among all of the research groups [4].

Table 2 reports the main engine characteristics of the representative engine model, and its schematic configuration is given in Fig. 3.

The engine is made up of two in-line four-cylinder banks with a bank angle of $90^{\circ}$. Each cylinder bank is fed by a

Table 2 Engine characteristics

\begin{tabular}{ll}
\hline Cycle & Diesel (four strokes) \\
\hline Total displacement & $20.08 \mathrm{dm}^{3}$ \\
No. of cylinder and arrangement & $8-\mathrm{V} 90$ \\
Valves per cylinder & 4 \\
Turbocharging & Turbo and intercooler \\
Intake air cooling & Single common charge cooler \\
Firing order & $1-3-7-2-6-5-4-8$ \\
Bore & $145 \mathrm{~mm}$ \\
Stroke & $152 \mathrm{~mm}$ \\
Compression ratio & $17.4: 1$ \\
IVO/IVC & $27.5^{\circ} \mathrm{BTDC} / 53.5^{\circ}$ ABDC \\
EVO/EVC & $66^{\circ} \mathrm{BBDC} / 22.5^{\circ}$ ATDC \\
Rated power & $560 \mathrm{~kW}$ @ 2100 rpm \\
Maximum torque & $3200 \mathrm{Nm} @ 1800 \mathrm{rpm}$ \\
EGR & High-pressure circuit with two \\
Injection system & separate coolers \\
Injection management & Common rail \\
\hline
\end{tabular}

Table 3 Weighting factors of C1 ISO 8178 test cycles

\begin{tabular}{lll}
\hline $\begin{array}{l}\text { Weighting } \\
\text { factors }\end{array}$ & Speed & $\begin{array}{l}\text { Torque } \\
(\%)\end{array}$ \\
\hline 0.15 & Rated & 100 \\
0.15 & & 75 \\
0.15 & & 50 \\
0.1 & Intermediate & 10 \\
0.1 & & 75 \\
0.1 & & 50 \\
0.1 & Low idle & 0 \\
0.15 & & \\
\hline
\end{tabular}

From [2]

turbocharger system. The two separate intake lines for each cylinder bank are connected primarily to the compressor and then to a common charge air cooler (CAC). Downstream of the $\mathrm{CAC}$, the intake line splits again into two ducts, one for each bank.

Concerning the exhaust layout, the exhaust gases from each cylinder bank are first collected in an exhaust manifold, and afterward, part is ducted to the turbine and part is redirected through the high-pressure EGR circuit (HP-EGR). The EGR gas stream is cooled and controlled by means of an EGR valve.

The engine operation points chosen for this study are those of the ISO 8178-4/F cycle-the C1 homologation cycle for non-road diesel engines [2]. Table 3 reports the test points in terms of speed, torque, and weighting factor for cumulative emission calculation on the $\mathrm{C} 1$ cycle and Fig. 1 shows the position of the points in the speed-load map. The ISO 8178 is an international standard designed for a number of non-road engine applications. It is used for emission certification approval in many countries worldwide, including the USA, European Union, and Japan [2]. Simulations were performed for all the $\mathrm{C} 1$ test points, apart from idle and the rated speed-10\% load test point. Since no calibration process of the onedimensional (1-D) engine model was possible at the latter two points, they were omitted in the study. Reference data from experimental measurements on brake-specific fuel consumption (BSFC), brake-specific nitrogen oxides (BSNOx), and the exhaust gas conditions and incylinder thermodynamic conditions at all the simulated test points were supplied by the industrial partners of the Cleaner-D consortium. The experimental data were used for calibration of 1-D and three-dimensional (3-D) CFD codes, and they refer to the reference engine without the after-treatment system and EGR.

According to the stage IV limits, a BSNOx target of $0.4 \mathrm{~g} /$ $\mathrm{kWh}$ (minus about $10 \%$ to take into account deterioration effects) was considered. 


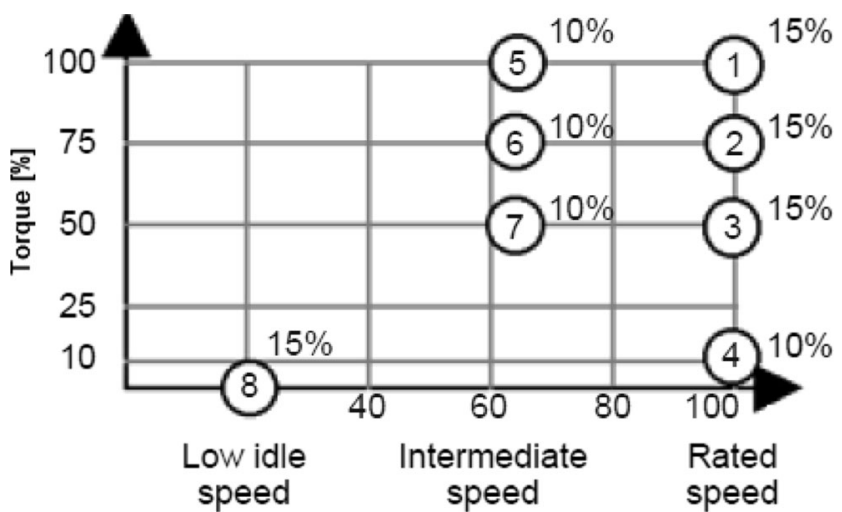

Fig. 1 Position of the test points in the speed load map

\section{Study Methodology}

In order to study these trade-offs on a quantitative basis, the approach has been to use CFD tools to predict the related performances of both the engine/EGR system and the aftertreatment system devices. In particular, a 1-D engine/EGR model, a 3-D diesel engine combustion model, and 1-D DPF and SCR models have been employed. The interaction between these models is shown in Fig. 2.

The study has been organized in two steps:

- Step 1 quantitatively studies the use of SCR or EGR + DPF state-of-the-art solutions on engine raw and tailpipe brake-specific NOx (BSNOx) emission and BSFC of a $560 \mathrm{~kW}$ for railcar application;

- Step 2 quantitatively studies the use of combined EGR + DPF + SCR state-of-the-art solutions to meet stage IV emissions targets.

In practice, the study has been performed in two phases:

- In the first phase, the 1-D engine/EGR and 3-D combustion models were developed and calibrated (using experimental data) in order to evaluate the impact of the EGR layout on the engine raw BSNOx and BSFC and to produce the input data for the after-treatment simulations.

- In the second phase, using 1-D CFD tools, the DPF and SCR devices were simulated and sized. First, simulations were performed separately; then, a combination of these devices was applied in order to match the tailpipe emission targets.

\subsection{DPF Characteristics}

A catalyzed DPF (CDPF) was considered in order to reduce PM emissions. It consisted of one or more cylindrical monolithic wall-flow substrates coated with a suitable catalyst to promote soot oxidation. The multi-monolith design was based on commercially available cylindrical silicon carbide monoliths with the characteristics shown in Table 4. Silicon carbide was chosen instead of cordierite because in a passively regenerating system, its higher thermal mass and thermal conductivity can provide a greater measure of safety against performance degradation or failure due to interactions between the substrate and ash under conditions of uncontrolled regeneration [5].

From a cost perspective, such a multi-monolith approach is likely due to the widespread availability of the monoliths on the market; further, the relatively small size of the monoliths allows for a flexible device design.

A ceria-based soot oxidation catalyst is assumed for passive regeneration of the CDPF at exhaust gas temperatures above approximately $400{ }^{\circ} \mathrm{C}$. A platinum catalyst for $\mathrm{NO}_{2} /$ NO conversion is not used; soot oxidation (direct and catalytic) by oxygen predominates over that of $\mathrm{NO}_{2}$-assisted since the oxygen concentration in the exhaust gas is relatively high while the NOx concentration is relatively low due to the EGR use. DPF regeneration performance is sensitive to the catalyst used, and the simulation results are sensitive to the kinetic parameters assumed for the catalyst. Therefore, the emphasis of the simulations was addressed on the trends of the total DPF monolith volume and on the regeneration performance more than on the absolute values.

\subsection{SCR Characteristics}

A SCR device can be considered for NOx emission control. Such a device consisted of one or more cylindrical monolithic
Fig. 2 Interaction between the engine/EGR, diesel engine combustion, DPF, and SCR models, used in the EGR-SCR analysis

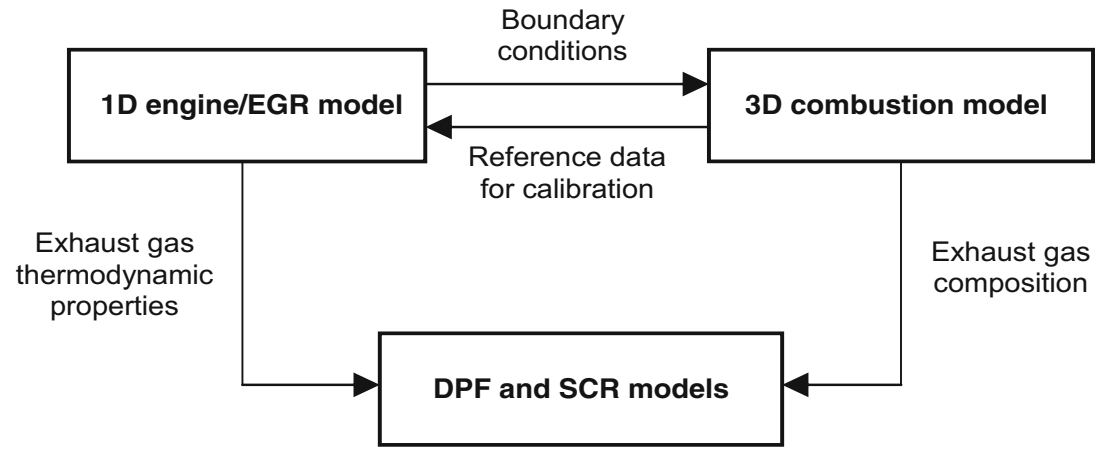


Table 4 DPF monolith characteristics

\begin{tabular}{ll}
\hline Characteristic & Value \\
\hline Cell density/channel wall thickness & $200 / 14 \mathrm{cpsi} / 10^{-3}$ in \\
Monolith diameter & $165 \mathrm{~mm}$ \\
Monolith length & $151 \mathrm{~mm}$
\end{tabular}

flow-through honeycomb substrates coated or manufactured from the active materials required for ammonia $\left(\mathrm{NH}_{3}\right)$ adsorption/desorption. On cost grounds, such a multi-monolith design is likely due to the widespread availability of suitable monoliths on the market. In order to facilitate a comparison between the SCR sizes for BSNOx target value, the monolith design (cell density, diameter, and length) was kept constant and only the number of monoliths was varied. The specifications of the monoliths employed are given in Table 5.

A vanadium-titanium catalyst was assumed with kinetic parameters fitted to the experimental results of using the SCR model described in the following [6-8]. Similar to the DPF, the SCR performance is sensitive to the catalyst used and the simulation results are sensitive to the kinetic parameters of the catalyst. Therefore, also in this case, the emphasis was addressed on the trends in total SCR monolith volume and urea consumption more than on the absolute values.

The use of a $32.5 \%$ aqueous urea solution is assumed as the source of ammonia since this is the eutectic composition which exhibits the lowest possible freezing temperature. Furthermore, it is assumed that a fast thermolysis and hydrolysis step (not modeled here) is performed in a preconverter immediately upstream of the SCR to convert completely urea into ammonia.

\subsection{Numerical Tools and Models}

\subsubsection{1-D CFD Model}

As a 1-D CFD tool, the GT-Power software was chosen. It is suitable for analysis of a wide range of issues related to vehicle and engine performances [9]. The code is generally used for the engine design and development of pipes, EGR, CAC, heat transfer, friction, etc. and, afterward, to predict steady-state conditions of the engine systems such as efficiencies, thermodynamic parameters, combustion rates, and emissions (BSNOx in the present case).

Table 5 SCR monolith characteristics

\begin{tabular}{ll}
\hline Attribute & Value \\
\hline Cell density/channel wall thickness & $300 / 8 \mathrm{cpsi} / 10^{-3}$ in \\
Monolith diameter & $241 \mathrm{~mm}$ \\
Monolith length & $152 \mathrm{~mm}$ \\
\hline
\end{tabular}

The models of the CAC and the EGR coolers were calibrated in order to match the reference data of the outlet CAC temperatures and EGR gas temperatures provided within the Cleaner-D consortium. The turbocharging system consists in a single-stage turbocharger equipped with a waste gate valve. A thermodynamic model was employed to simulate the turbocharger and to match the available reference data. The simulation of the waste gate valve is implicitly included in the model. Figure 3 shows the scheme of the GT-Power engine model.

A zero-dimensional multi-zone model has been employed in the 1-D CFD tool to simulate the combustion. It is called DI-Jet in the GT-Power simulation platform [9]. The model is able to predict, to some extent, the combustion rate, NOx, and $\mathrm{CO}$ emissions of direct-injection diesel engines. In order to provide an accurate prediction, the combustion model has been calibrated to match the cylinder pressure profile, the NOx emissions, and the exhaust temperatures provided as reference experimental data. Input data for the calibration were all the engine boundary conditions (air mass flow, intake temperatures, and pressure, etc.) and the injection rate profiles. The engine model predictivity was validated for some engine test conditions characterized by different speeds, loads, and EGR levels. Table 6 reports the test points and operating conditions selected for 1-D model validation.

As an example, Fig. 4 displays a comparison between the 1-D engine model output results in terms of cylinder pressure, heat release (HR) and heat release rate (HRR), and the reference experimental data, for the calibrated DI-Jet combustion model. In particular, these figures refer to test at $2100 \mathrm{rpm}$, $100 \%$ load, and $0 \%$ EGR. For sake of brevity, the comparison at the test points is omitted.

Concerning the exhaust line, the presence of the aftertreatment devices (DPF or/and SCR) in the simulations has been considered by imposing local and distributed pressure losses in order to reproduce realistic exhaust backpressure (Pback) values [7]. The Pback is a function of the exhaust line configuration, the engine operating conditions, and the soot mass loaded in the CDPF, and all possible scenarios have been considered in the 1-D simulations (see Table 8 in the following).

\subsubsection{3-D CFD Model}

A full-engine-cycle CFD model based on the KIVA-4 code [10] and coupled with detailed chemistry combustion kinetics [11] was employed in order to generate exhaust manifold emissions data for the design and modeling of exhaust aftertreatment systems. Computational sub-models used in the study are listed in Table 7, and model details can be found in [12]. A generic diesel engine mesh, as shown in Fig. 5, was designed in compliance with the geometric specifications stated in Table 2. Combustion system specifications for mesh 
Fig. 3 Schematic of the engine model

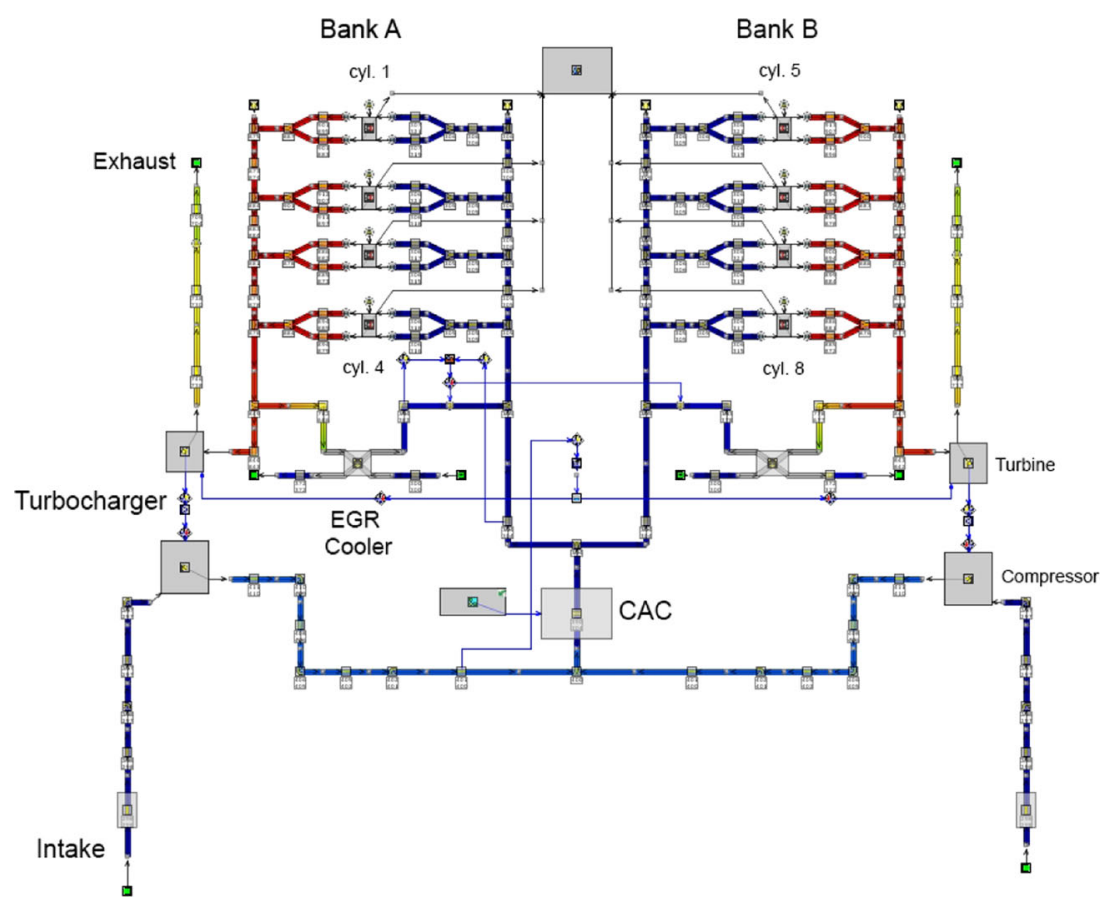

design and boundary conditions (e.g., injection profile) were provided within the Cleaner-D consortium.

As illustrated in Fig. 2, engine operating and boundary conditions for 3-D CFD simulations were determined by the 1-D engine simulations. The dynamic pressure and temperature boundary conditions at the exhaust valves were obtained from the 1-D engine simulations for the empty and the loaded DPF scenarios.

Figure 6 shows the effect of EGR on reducing the incylinder local temperatures, leading to less NO formation. Iso-volumes changing from yellow to red represent the temperature range between 1800 and $2200 \mathrm{~K}$, respectively. At $30 \%$ EGR conditions, it is evident a significant decrease of the local temperatures.

\subsubsection{DPF and SCR System Models}

One-dimensional models are employed to size and simulate DPF and SCR devices for the $560-\mathrm{kW}$ engine. The models use, as input data, the exhaust gas conditions predicted by the 1-D engine and 3-D CFD codes, and devices are sized to

Table 6 Reference operating points for calibration of DIJet combustion model

\begin{tabular}{llll}
\hline Operating point & Speed (rpm) & Load (\%) & EGR (\%) \\
\hline $1350 @ 50 \%$ & 1350 & 50 & 0 \\
$1350 @ 100 \%$ & 1350 & 100 & 0 \\
$2100 @ 100 \%$ & 2100 & 100 & $0,10,25$ \\
\hline
\end{tabular}

comply with the exhaust backpressure range of the engine. Both models account for the major functionalities of current state-of-the-art DPF and SCR technologies used in the road sector and are employed on the assumption that the same technologies will also be used as a matter of first choice in diesel railcar applications to meet stage IV emission limits.

A perimeter-averaged, stream-wise spatial, coordinatedependent, so-called "single-channel" model is used to simulate the physicochemical phenomena occurring inside a single representative channel of the DPF monoliths, and it is the standard practice to employ such a model for any initial design study. The single-channel model is identical to a full 3-D model in the case of radially uniform inlet exhaust gas mass flow and temperature distributions across a radially insulated monolith. These attributes are also system design targets to ensure optimal regeneration performance of the DPF. The model accounts for all the flow resistances across the monolith (inlet/outlet losses, wall friction, flow through the soot deposit, and porous wall), gas species, and soot particle transport along the channels, soot particle filtration (the particular coated $\mathrm{SiC}$ filter employed exhibits $100 \%$ filtration efficiency for solid soot aggregates almost immediately), and soot deposit oxidation. Convective heat transport along the channels and through the porous walls and conductive heat transport in the walls and the soot deposit are also accounted for. The model employs reaction paths for thermal and catalytic soot oxidation by oxygen, soot oxidation by $\mathrm{NO}_{2}, \mathrm{CO}$ oxidation, $\mathrm{NO}$ oxidation to $\mathrm{NO}_{2}$, and hydrocarbon oxidation (represented by $\mathrm{C}_{3} \mathrm{H}_{6}$ ). Additional details on the model can be found in [13-19]. 

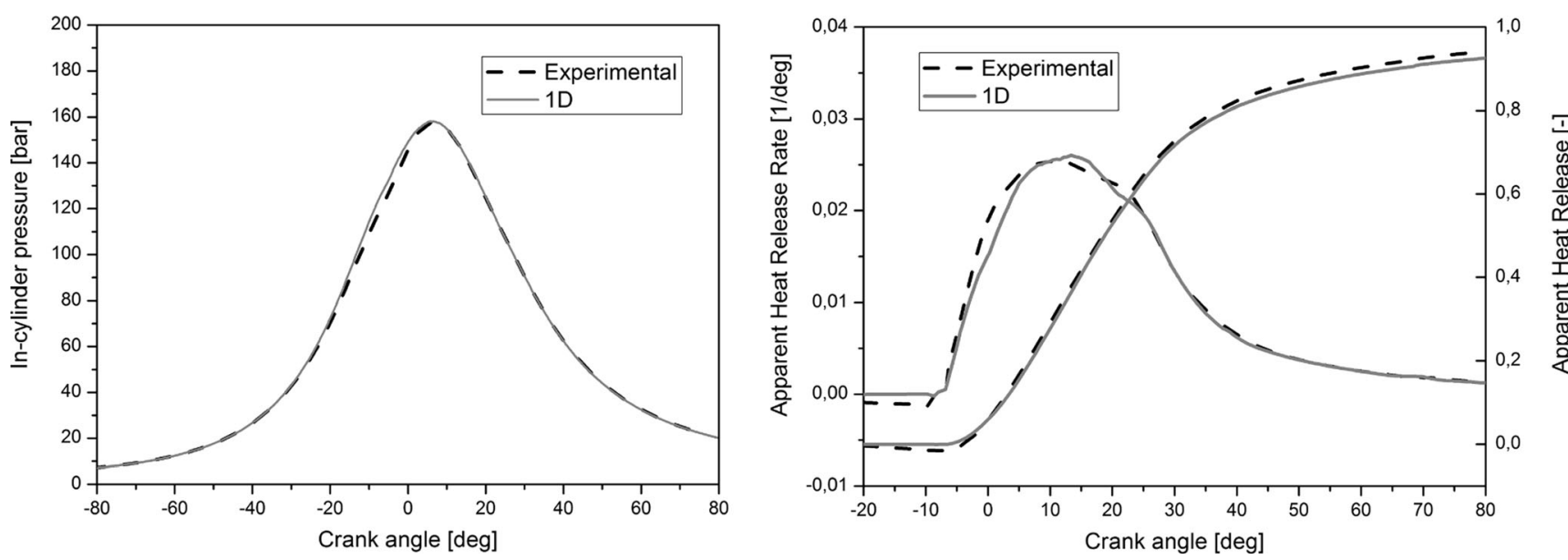

Fig. 4 Cylinder pressure, HRR, and HR comparisons between numerical data from 1-D CFD simulation and the experimental one, at $2100 \mathrm{rpm}$ and $100 \%$ load without EGR

A single-channel model is also used to simulate the physicochemical phenomena occurring inside the SCR device. The model is based on the implementation of the work of the group of Tronconi, described in detail in [20,21], into the standard transport model of a flow-through catalytic monolith. Additional details on the model can also be found in [22]. It is assumed that ammonia $\left(\mathrm{NH}_{3}\right)$ enters the monoliths after a fast thermolysis and hydrolysis step of urea in a preconverter (not modeled here). Likewise, this model is valid under conditions of radially uniform exhaust gas flow, temperature, and ammonia distributions, and this is also a design target to ensure optimal performance of the device. The flow is assumed to be adiabatic since the enthalpy of the SCR reactions is small. The model accounts for the transient nature of ammonia adsorption/desorption, NOx reduction by ammonia and ammonia oxidation. NOx reduction is modeled via the "standard, " "fast," and "slow" SCR reactions, so-called because of their relative rates [6]. The standard reaction concerns NO reduction, the fast reaction simultaneous $\mathrm{NO}$ and $\mathrm{NO}_{2}$ reduction, while the slow reaction concerns only $\mathrm{NO}_{2}$ reduction. The oxidation of ammonia occurs at appreciable rates at relatively high temperatures (greater than about $400{ }^{\circ} \mathrm{C}$ ) and results in a

\section{Table 7 Computational models}

\begin{tabular}{ll}
\hline Turbulence model & RNG k- $\varepsilon$ model \\
\hline Breakup model & Hybrid KH-RT model \\
Collision model & Droplet trajectories \\
Spray/wall interaction model & Original KIVA-4 model \\
Heat transfer model & Original KIVA-4 model \\
Evaporation model & Single component, KIVA-3V \\
Combustion model & Detailed Arrhenius kinetics \\
Turbulence/chemistry interaction & PaSR model and Arrhenius kinetics \\
Soot formation and oxidation & Semi-empirical and surface kinetics \\
NOx mechanism & Extended Zel'dovich \\
\hline
\end{tabular}

degradation of SCR performance that must also be considered. Figure 7 illustrates the main SCR transport and reaction phenomena considered in the model.

A reaction network approach is used to calculate the chemical species sources in the gas phase and on the channel walls. Furthermore, overall mass, energy, and species mass conservation are considered in the gas phase and on the channel walls. The model equations are solved numerically employing finite analytic/finite volume methods.

\subsubsection{Simulation Methodology}

A methodology for the simulation process was defined in order to set all of the boundary conditions and the engine control criteria.

From the engine point of view, combustion parameters were kept constant as resulted from the validation phase. In

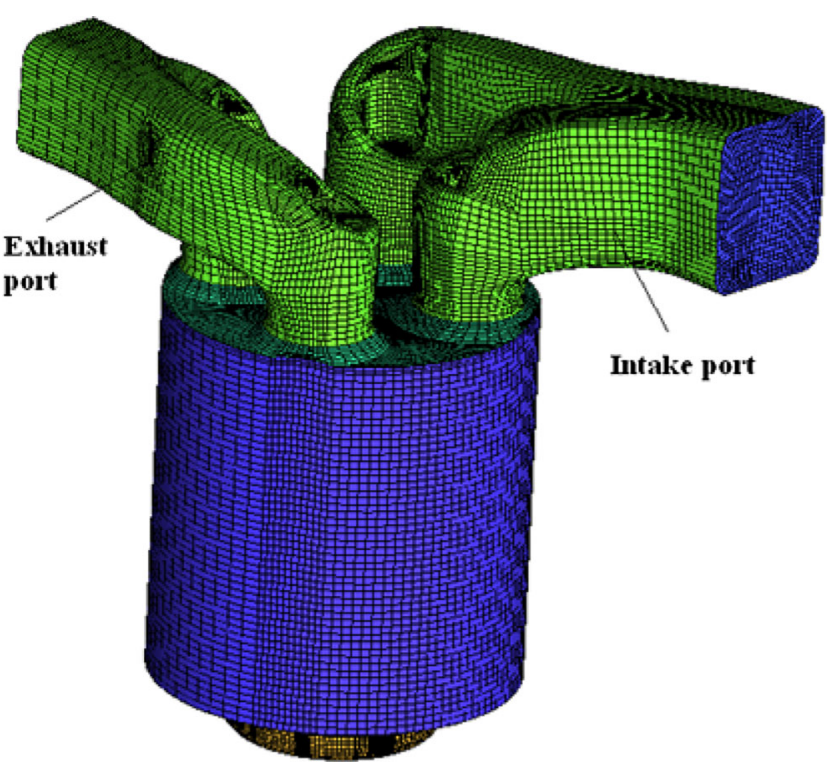

Fig. 5 Generic engine mesh consisting of about 600,000 cells 

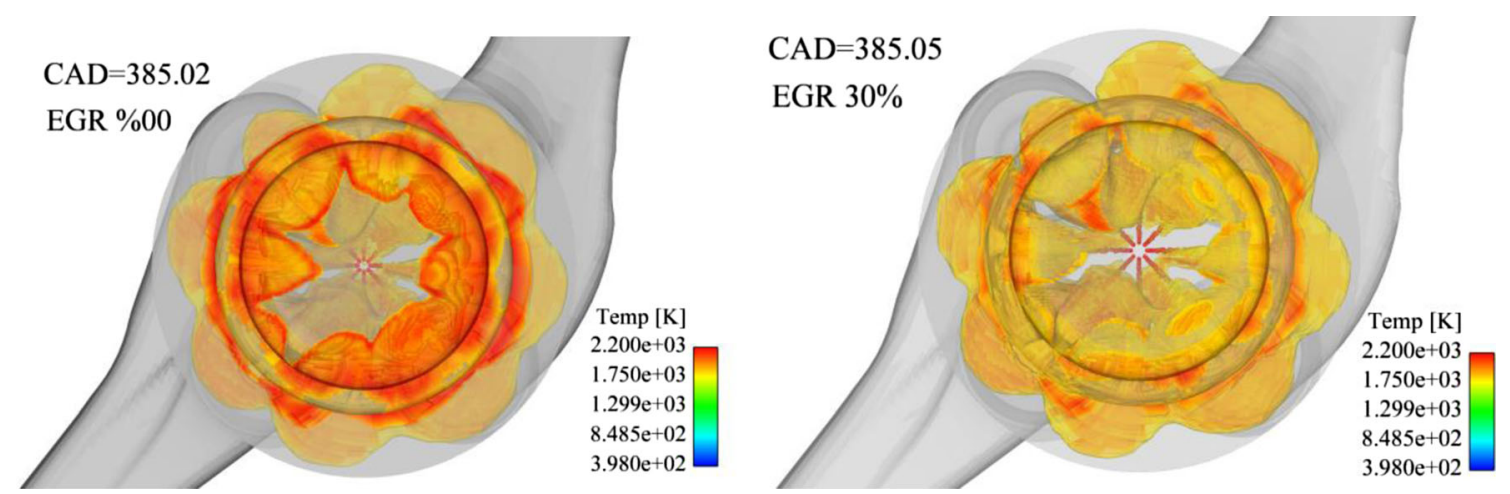

Fig. 6 Bottom view of combustion chamber for EGR effect on reducing the local temperatures: EGR-free conditions (a) and 30 \% EGR application (b)

addition, in all explored test conditions, the start of injection (SOI) was varied in order to realize an optimum combustion phasing ( $50 \%$ of the burned fuel mass (MBF50\%) in the crank angle $-(\mathrm{CA})$ window of $9 \div 12$ after top dead center (ATDC)) and to keep the peak firing pressure (pfp) limit within 210 bar [7].

In terms of EGR control methodology, two control modes were explored by means of simulation sweeps. In the first strategy, the EGR rate, the SOI, and the fuel injected mass were controlled to keep constant the boost pressure, the MBF50 \%, and the power, respectively. This approach was called the constant boost $(\mathrm{CB})$. In this case, the maximum attainable EGR rate is limited by a minimum air-fuel ratio (A/F) corresponding to the prefixed limit on PM emissions. The minimum A/F was imposed as boundary condition on the base of the 3-D CFD calculations. The second strategy considers the possibility to keep constant the intake air mass flow by increasing the boost pressure and reducing discharged flow from the waste gate valve. With this approach, called the constant lambda (CL), the EGR rate is limited by the available energy for the turbocharger to increase the boost pressure.

As concerns the Pback setting, the boundary conditions relative to three after-treatment setups were considered: the first concerns the EGR + DPF only, considering both the case of empty and loaded DPF; the second concerns the SCR only, without the use of EGR for the NOx control; the third concerns the use of all of the devices EGR + DPF + SCR. For each configuration, the Pback values were properly estimated taking into account the nominal pressure drop of the exhaust line, the empty DPF, the loaded DPF, and the SCR. Table 8

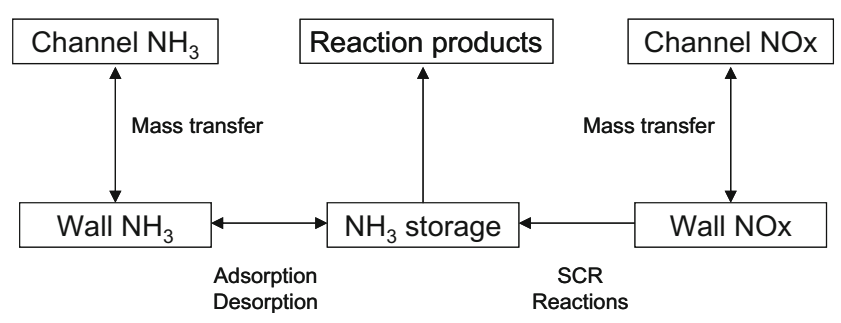

Fig. 7 Physicochemical phenomena modeled in the SCR reports the EGR control strategies and the Pback set values for all explored conditions at rated speed.

Following the simulation approach described above, the 1$\mathrm{D}$ results provided a complete overview of the engine response for the three considered after-treatment layouts in terms of BSFC and BSNOx emissions trade-off versus EGR rate for both the EGR control strategies, while the soot emission prediction was demanded to the 3-D CFD simulations.

The engine data from the 1-D and 3-D simulations, relative to the best compromise in terms of BSNOx and FC, were considered as input for the DPF and SCR simulations and sizing, as described in Sect. 2.4.3. Both the DPF and SCR devices must conform to the design backpressure range of the engine, as reported in Table 8 . More in details, the allowable monolith pressure drop is 50 mbar in the case of the unloaded DPF and SCR, with an additional 100-mbar pressure drop allowance for soot loading in the case of the DPF only.

The final result was the quantitative impact of the DPF, SCR, and their combinations on the BSNOx and BSFC over the $\mathrm{C} 1$ test cycle, with a unique optimized EGR strategy.

\section{Results and Discussion}

\subsection{1-D Simulation of Engine with EGR}

For sake of brevity, the simulation results relative to the engine at rated power (2100 rpm and $100 \%$ load) equipped with a loaded DPF are presented in this section.

With respect to the two EGR strategies, CB and CL, Fig. 8 shows the trends in terms of BSNOx and BSFC versus EGR at engine rated power. From Fig. 8, it is immediate to note that the EGR CB control strategy is quite limited as maximum rate, while the same BSNOx can be reached with the CL strategy if the engine accepts an increase of the boost pressure. The areas in between the two control strategies define the potential intermediate operating points adopting hybrid $\mathrm{CB} / \mathrm{CL}$ control strategies. The best compromise between BSNOx and BSFC is indicated with a circle, and the correspondent boost pressure was about 2.7 bar. 
Table 8 Engine simulation matrix with relative Pback values at rated speed

\begin{tabular}{llll}
\hline $\begin{array}{l}\text { Explored engine } \\
\text { conditions }\end{array}$ & EGR strategies & Configuration & Backpressure \\
\hline (a) & $\begin{array}{c}\text { EGR sweep with const. } \\
\text { lambda/boost } \\
\text { EGR sweep with const. } \\
\quad \text { lambda/boost }\end{array}$ & EGR + DPF (filter empty) & Pback=150 mbar \\
& $\begin{array}{l}\text { No EGR } \\
\text { EGR sweep with const. } \\
\text { lambda/boost }\end{array}$ & EGR (filter loaded) & Pback=250 mbar \\
(c) & EGR sweep with const. & EGR + DPF + SCR (filter loaded) & Pback=300 mbar \\
& lambda/boost & & \\
\hline
\end{tabular}

A similar assessment was made in the other points of the C1 homologation cycle. Table 9 reports the simulation results for all the test points of the $\mathrm{C} 1$ test cycle, employing an EGR CL control strategy and the maximum Pback, corresponding to the DPF + SCR configuration. The last row in Table 9 indicates that a BSNOx target of $2 \mathrm{~g} / \mathrm{kWh}$ on $\mathrm{C} 1$ test cycle, about $10 \%$ below the stage IIIB, seems to be attainable with a standard HP-EGR system and without significant FC penalty with respect to the case without EGR (see plot in Fig. 8).

\subsection{3-D Simulation of Soot and NOx Engine Raw Emissions}

In order to generate proper input data for the DPF and SCR simulations, the brake-specific soot emissions (BSsoot) and BSNOx were carried out by means of KIVA 3-D simulation in all the operating points of the $\mathrm{C} 1$ test cycle, adopting the optimum EGR strategy as from 1-D calculations. For sake of brevity, the summary of the engine raw BSsoot and BSNOx, as predicted by the $3-\mathrm{D}$ computations, is given in Table 10. It is worth to note that over the $\mathrm{C} 1$ test cycle, the 1-D and the 3D calculations yield very similar BSNOx.

\subsection{1-D Simulation of the DPF}

The DPF was sized to reduce the soot particle emissions of the engine equipped with EGR to below the stage IIIB limit while meeting the target clean filter pressure drop of 50 mbar at rated power. More in details, the engine raw soot particle emissions were reduced from $0.100 \mathrm{~g} / \mathrm{kWh}$ to below $0.005 \mathrm{~g} / \mathrm{kWh}$ over the $\mathrm{C} 1$ test cycle (the contribution of the organic fraction to total PM emissions was neglected in the present study), therefore well below the stage IV limit and also the proposed stage $\mathrm{V}$. With respect to this target, the DPF sizing indicates that six monoliths were required for a monolith pressure drop of 40 mbar at rated power, resulting in a total monolith volume of $19.3 \mathrm{dm}^{3}$.

The passive regeneration behavior of the DPF has been simulated at the $\mathrm{C} 1$ points of 75 and $50 \%$ load at intermediate speed $(1575 \mathrm{rpm})$ and rated speed $(2100 \mathrm{rpm})$. The results at $2100 \mathrm{rpm}$ and $100 \%$ load, and $1575 \mathrm{rpm}$ and $50 \%$ load are shown in Figs. 9 and 10. It resulted that for the operating points with the exhaust gas temperature below about $400{ }^{\circ} \mathrm{C}$ (2100 rpm-100\% load, $1575 \mathrm{rpm}-100$ and $75 \%$ load), it was not possible to reach an equilibrium soot mass load and the filter continued loading indefinitely. However, the required
Fig. 8 BSNOx and BSFC versus EGR at rated power $(2100 \mathrm{rpm}$ full, $100 \%$ load) for a Pback corresponding to a loaded DPF

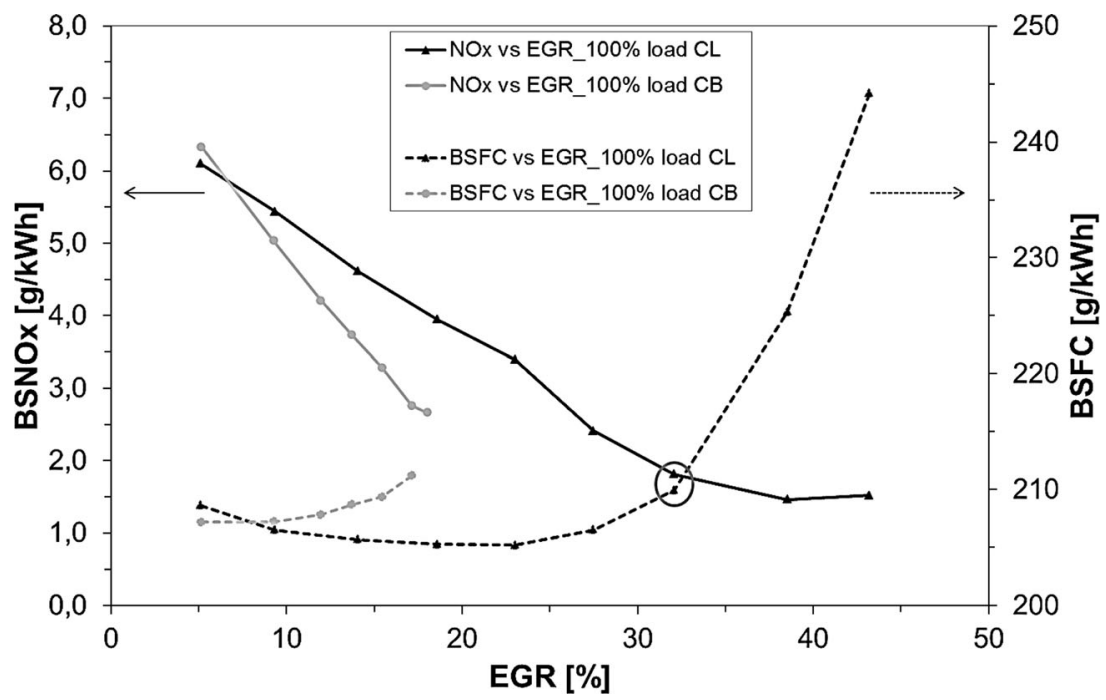


Table 9 Computed BSNOx and BSFC over the $\mathrm{C} 1$ test cycle with an optimized EGR control strategy and the maximum Pback of $250 \mathrm{mbar}$

\begin{tabular}{lllllll}
\hline Speed (rpm) & Load (\%) & Weigh factor & $\begin{array}{l}\text { Power } \\
(\mathrm{kW})\end{array}$ & EGR (\%) & $\begin{array}{l}\text { BSNOx } \\
(\mathrm{g} / \mathrm{kWh})\end{array}$ & $\begin{array}{l}\text { BSFC } \\
(\mathrm{g} / \mathrm{kWh})\end{array}$ \\
\hline 2100 & 100 & 0.15 & 560 & 32 & 1.81 & 209.9 \\
& 75 & 0.15 & 422 & 20 & 2.06 & 217.0 \\
& 50 & 0.15 & 286 & 25 & 2.00 & 225.2 \\
1575 & 10 & 0.1 & 56 & $\mathrm{NA}^{\mathrm{a}}$ & 1.42 & $250.0^{\mathrm{a}}$ \\
& 100 & 0.1 & 513 & 38 & 1.15 & 192.7 \\
& 75 & 0.1 & 388 & 38 & 1.73 & 188.8 \\
Idle & 50 & 0.1 & 263 & 25 & 2.13 & 199.2 \\
Weighted performance on C1 test cycle & 0.15 & 2 & 0 & 0.04 & 0.0 \\
\hline
\end{tabular}

${ }^{a}$ The data at $10 \%$ of load are not simulated but derived from available experimental data time to reach the critical soot mass load at which active regeneration should be activated (to avoid dangerous uncontrolled regeneration, e.g., $4-5 \mathrm{~g} / \mathrm{dm}^{3}$ of monolith) was found to be, in general, greater than about $10 \mathrm{~h}$. The same time was to reach the maximum incremental pressure drop due to soot loading permitted within the allowable Pback range (100 mbar). At the other operating points, an equilibrium soot mass load was reached within 2-3 h of steady-state operation that was well below the critical value. Therefore, it appears probable that the engine switch to a high exhaust gas temperature operating point before the critical soot mass load was reached. In this case, the DPF could undergo on partial regeneration and shift to a lower soot mass load. However, it is important to remark that the described DPF behavior was specific for the modeled engine and DPF and the assumed DPF catalyst performance.

\subsection{1-D Simulation of the SCR}

The SCR device was simulated and sized in order to match the BSNOx target of $0.9 \mathrm{~g} / \mathrm{kWh}$ for engine operating conditions without EGR use. In this case, the monolith pressure drop did not exceed 50 mbar. A uniform catalyst loading of $2 \times$ $10^{-7} \mathrm{~mol} / \mathrm{cm}^{2}$ (areal density of active sites for ammonia adsorption) was assumed. This loading ensured, on the one hand, that the adsorbed ammonia never exceeded $50 \%$ of the available ammonia storage capacity of the monoliths, and, on the other hand, that an excessive amount of catalyst was not used. Furthermore, the number of monoliths (operating in parallel) was chosen so that the residence time was sufficient to ensure almost complete conversion of the

Table 10 BSsoot and BSNOx data over the $\mathrm{C} 1$ test cycle as predicted by the 3 -D computations

\begin{tabular}{ll}
\hline BS soot $(\mathrm{g} / \mathrm{kWh})$ & BSNOx $(\mathrm{g} / \mathrm{kWh})$ \\
\hline 0.100 & 1.61 \\
\hline
\end{tabular}

ammonia in the first $50 \%$ of channel length at all operating points. Thus, the SCR design has built in a sufficient but not excessive margin of safety against ammonia slip.

The SCR was sized by specifying the number of monoliths and then by determining, at each operating point, the inlet ammonia concentration required to reduce the tailpipe BSNOx at the target value, without saturating the ammonia storage capacity of the monolith or exceeding the allowable ammonia slip limit (5-10 vppm). Then, based on the exhaust mass flow rate, the inlet ammonia concentration was translated into an ammonia consumption rate, from which the brake-specific urea consumption (BSUC) was calculated.

To achieve the BSNOx target of $0.9 \mathrm{~g} / \mathrm{kWh}(50 \%$ of the stage IIIB limit, including $10 \%$ of safety margin), a SCR employing four monoliths was necessary. The total monolith volume was $27.9 \mathrm{dm}^{3}$. The pressure drop of the monoliths at rated power was approximately 14 mbar. As shown in Table 11, SCR was performed at all operating points on the C1 test cycle apart from $2100 \mathrm{rpm}-10 \%$ load and idle, at which the exhaust gas temperature was too low for the SCR functionality. The BSUC over the $\mathrm{C} 1$ cycle was estimated about $24.1 \mathrm{~g} / \mathrm{kWh}$.

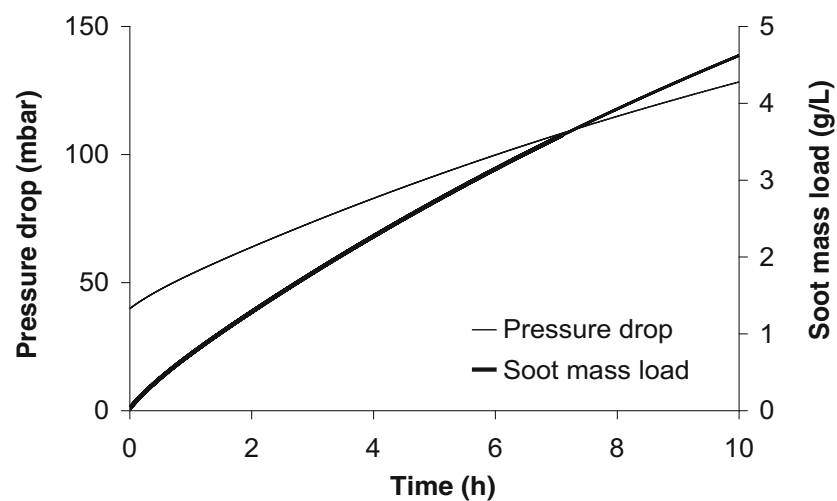

Fig. 9 Evolution of DPF monolith pressure drop and soot mass load at $2100 \mathrm{rpm}-100 \%$ load (exhaust temperature $365^{\circ} \mathrm{C}$ ) 


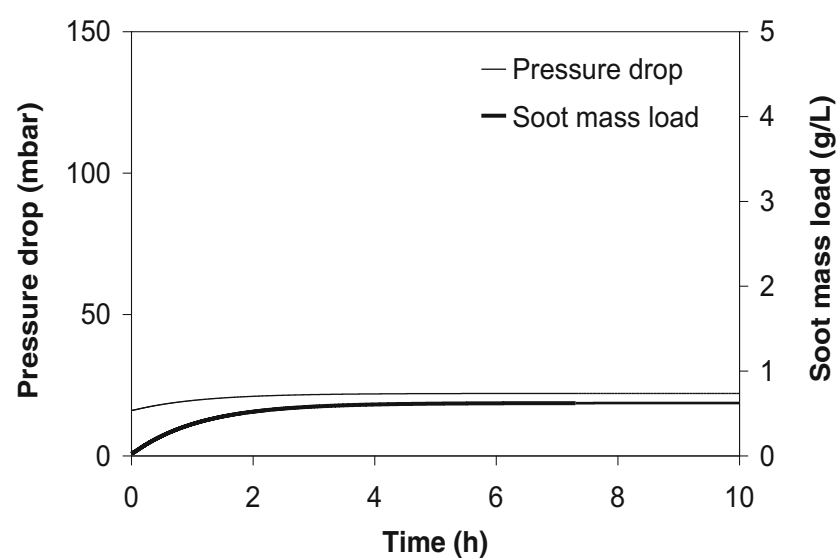

Fig. 10 Evolution of DPF monolith pressure drop and soot mass load at $1575 \mathrm{rpm}-50 \%$ load (exhaust temperature $422^{\circ} \mathrm{C}$ )

By looking at the BSUC values and BSUC/BSFC ratio reported in Table 11, a remarkable urea consumption for matching the $0.9 \mathrm{~g} / \mathrm{kWh}$ of BSNOx with a $560-\mathrm{kW}$ engine over the $\mathrm{C} 1$ test cycle is seen. In practice, an order of magnitude with respect to the $\mathrm{FC}$ and without matching the stage IV BSNOx target is not feasible. Therefore, the combination of the EGR + DPF and the SCR was also evaluated.

\subsection{Simulation of the Combination of DPF + EGR and SCR}

The architecture employing all devices $(\mathrm{EGR}+\mathrm{DPF}+$ SCR) was examined. In this case, assuming the engine working with an EGR control strategy as in Table 9 (with engine raw BSNOx of $1.8 \mathrm{~g} / \mathrm{kWh}$ ), the SCR was sized for a BSNOx target over the $\mathrm{C} 1$ test cycle of $0.4 \mathrm{~g} / \mathrm{kWh}$ (as required from the stage IV regulation). As $10 \%$ of safety margin was assumed in order to try to compensate the model uncertainties, the material properties,

Table 11 SCR performance for all the test points for a BSNOx target of $0.9 \mathrm{~g} / \mathrm{kWh}$ over the $\mathrm{C} 1$ test cycle

\begin{tabular}{llllll}
\hline $\begin{array}{l}\text { Engine } \\
\text { speed (rpm) }\end{array}$ & $\begin{array}{l}\text { Engine load } \\
(\% \text { rated })\end{array}$ & $\begin{array}{l}\text { Inlet } \\
\mathrm{NH}_{3} / \mathrm{NOx}\end{array}$ & $\begin{array}{l}\mathrm{BSNOx} \\
(\mathrm{g} / \mathrm{kWh})\end{array}$ & $\begin{array}{l}\mathrm{BSUC} \\
(\mathrm{g} / \mathrm{kWh})\end{array}$ & $\begin{array}{l}\mathrm{BSUC}^{\mathrm{B}} \\
\mathrm{BSFC}(\%)\end{array}$ \\
\hline 2100 & 100 & 1.32 & 0.69 & 34.9 & 16.9 \\
& 75 & 0.99 & 0.66 & 21.6 & 10.4 \\
& 50 & 0.89 & 0.73 & 17.5 & 8.1 \\
& 10 & 0.00 & 9.41 & 0.0 & 0.0 \\
1575 & 100 & 0.96 & 0.64 & 22.5 & 11.8 \\
& 75 & 0.91 & 0.74 & 20.8 & 10.8 \\
& 50 & 0.90 & 0.73 & 19.6 & 9.9 \\
Idle & 0 & 0.00 & - & - & - \\
Weighted performance & & 0.87 & 24.1 & \\
\multicolumn{2}{l}{ on C1 test cycle } & & & & \\
\hline
\end{tabular}

${ }^{a}$ BSFC values at 150 -mbar exhaust backpressure manufacturing processes, catalyst aging, etc. Thus, the SCR was sized for a BSNOx target $0.35 \mathrm{~g} / \mathrm{kWh}$. The same DPF design and performance are assumed as computed in Sect. 3.3. Furthermore, the SCR was assumed to be located downstream of the DPF.

For simplicity, the exhaust gas conditions at the SCR inlet were assumed to be the same as those at the DPF inlet. However, to support the approximation, it is necessary to consider that

- Under continuous DPF regeneration, the HR rate from the soot oxidation reactions is small, and therefore, the exhaust gas temperature does not change much in the DPF (which should be well insulated for optimum regeneration performance).

- There is an excess of oxygen in the exhaust gas, and therefore, the change in oxygen concentration due to the soot oxidation reactions can be neglected.

- The use of a diesel oxidation catalyst (DOC) was neglected. Thus, in the absence of a DOC, the NO/NOx ratio is close to one, and therefore, $\mathrm{NO}_{2}$-assisted soot oxidation in the DPF can be neglected. Likewise, SCR of $\mathrm{NO}_{2}$ accounts for only a small fraction of overall $\mathrm{NOx}$ reduction in the SCR.

However, the temperature of the exhaust gas was assumed to decrease by $10^{\circ} \mathrm{C}$ between the DPF and SCR due to heat losses to the environment in the urea mixing pipe section. The SCR design criteria were kept the same as in Sect. 3.2, and only the number of monoliths employed and the urea delivery rate are varied.

The SCR sizing resulted in four monoliths. The total monolith volume is $27.9 \mathrm{dm}^{3}$, while the pressure drop of the monolith at rated power was approximately 9 mbar. The estimated device weight and volume were $100 \mathrm{~kg}$ and $310 \mathrm{dm}^{3}$,

Table 12 SCR performance for all the test points for a BSNOx target of $0.9 \mathrm{~g} / \mathrm{kWh}$ over the $\mathrm{C} 1$ test cycle

\begin{tabular}{|c|c|c|c|c|c|}
\hline $\begin{array}{l}\text { Engine } \\
\text { speed (rpm) }\end{array}$ & $\begin{array}{l}\text { Engine load } \\
\text { (\% rated) }\end{array}$ & $\begin{array}{l}\text { Inlet } \\
\mathrm{NH}_{3} / \mathrm{NOx}\end{array}$ & $\begin{array}{l}\text { BSNOx } \\
(\mathrm{g} / \mathrm{kWh})\end{array}$ & $\begin{array}{l}\text { BSUC } \\
(\mathrm{g} / \mathrm{kWh})\end{array}$ & $\begin{array}{l}\mathrm{BSUC}^{\mathrm{a}} \\
\mathrm{BSFC}^{\mathrm{a}}(\%)\end{array}$ \\
\hline \multirow[t]{4}{*}{2100} & 100 & 0.71 & 0.28 & 2.1 & 1.0 \\
\hline & 75 & 1.08 & 0.33 & 8.2 & 3.8 \\
\hline & 50 & 0.89 & 0.29 & 6.0 & 2.7 \\
\hline & 10 & 0.00 & 1.42 & 0.0 & 0.0 \\
\hline \multirow[t]{3}{*}{1575} & 100 & 0.60 & 0.34 & 1.6 & 0.8 \\
\hline & 75 & 0.76 & 0.32 & 3.1 & 1.6 \\
\hline & 50 & 0.84 & 0.33 & 5.2 & 2.6 \\
\hline Idle & 0 & 0.00 & - & - & - \\
\hline \multicolumn{3}{|c|}{$\begin{array}{l}\text { Weighted performance } \\
\text { on } \mathrm{C} 1 \text { test cycle }\end{array}$} & 0.33 & 24.1 & \\
\hline
\end{tabular}

${ }^{\mathrm{a}} \mathrm{BSFC}$ values at 150-mbar exhaust backpressure 
respectively. Simulations were performed at all operating points apart from $2100 \mathrm{rpm}-10 \%$ load and idle, where the exhaust temperature is too low for the SCR functionality. The simulations indicated that steady-state conditions were reached at all operating points in $1 \div 2$ min after the start of urea delivering. Furthermore, ammonia slip is predicted not to exceed $1 \mathrm{vppm}$.

Table 12 reports the simulation results in terms of BSNOx and BSUC over the $\mathrm{C} 1$ test cycle. Simulations indicated also that a three-monolith design might also be adequate instead of a four-monolith design, since the pressure drop could further increase without penalty on engine performance. However, with three-monolith design, the design criterion of achieving almost complete ammonia conversion within the first $50 \%$ of channel length could be exceeded at certain operating conditions; therefore, a design employing four monoliths appears suitable for this case study. As observed from Table 12, the stage IV BSNOx limit can be reached with remarkably lower BSUC. On the contrary, the total volume of the whole aftertreatment system and the relative weight is a challenge for vehicle designers.

\section{Conclusions}

The present study investigated the impact of the use of EGR, DPF, and SCR devices on pollutant emissions, fuel, and urea consumption for a $560-\mathrm{kW}$ diesel engine as a railcar application with respect to the stage IV emission limits and beyond. The study was a part of the work program carried out in the FP7 European Cleaner-D project.

A methodology based on the combined use of 1-D and 3-D CFD tools was specifically developed for the study. Engine and EGR were modeled by means of GT-Power and KIVA 4$\mathrm{V}$ platform in order to provide accurate predictions of the engine raw emissions. Proprietary 1-D models were used for DPF and SCR simulation and sizing. The industrial partners of the Cleaner-D project provided an experimental dataset for the model validation.

The results reveal that the use of the EGR + DPF configuration has potential to reach PM emission limits, beyond the stage IV and for the proposed stage V, with an acceptable impact on FC and engine performance. However, this configuration could not meet the stage IV BSNOx limits. Achieving desired NOx levels by using only SCR, assuming that the engine measures are able to control PM emissions, is feasible for stage IV BSNOx, but it requires a remarkable on-board urea storage and consumption: about an order of magnitude with respect to BSFC. However, with a proper combination of the all the considered devices (EGR + DPF + SCR), stage IV targets can be approached with reasonable impact on fuel and urea consumption. In this last case, the total volume of the whole after-treatment system and the relative weight become a challenging task for rail powertrain designers.

Acknowledgments The authors want to thank the European Commission for funding this work through the Clean European Rail-Diesel project Seventh Framework Programme 7.2.1.1—Sustainable Surface Transport

\section{References}

1. Johnson, T.: Vehicular emissions in review. SAE Int J Engines 7(3), 1207-1227 (2014). doi:10.4271/2014-01-1491

2. www.dieselnet.com

3. Environmental Energy Agency report. "Change in emissions by transport sub-sector for NOX and PM2.5 (EEA-32)", 2009. http://www.eea.europa.eu/data-and-maps/figures/change-inemissions-by-transport

4. www.cleaner-d.eu

5. Merkel, G.A., Cutler, W.A., Warren, C.J.: "Thermal Durability of Wall-Flow Ceramic Diesel Particulate Filters", SAE Tech. Paper, 2001-01-0190

6. Koebel, M., Madia, G., Elsener, M.: Selective catalytic reduction of $\mathrm{NO}$ and $\mathrm{NO}_{2}$ at low temperatures". Catal Today 73, 239-247 (2002)

7. Beatrice, C., Rispoli, N., Di Blasio, G., Patrianakos, G. et al.: "Emission Reduction Technologies for the Future Low Emission Rail Diesel Engines: EGR vs SCR," SAE Technical Paper 201324-0087, 2013, doi:10.4271/2013-24-0087

8. Winkler, C., Florchinger, P., Patil, M.D., Gieshoff, J., Spurk, P., Pfeifer, M.: "Modeling of SCR DeNOx Catalyst—Looking at the Impact of Substrate Attributes", SAE Tech. Paper, 2003-01-0845.

9. https://www.gtisoft.com/

10. Torres, D.J., Trujillo, M.F.: KIVA-4: an unstructured ALE code for compressible gas flow with sprays. J Comput Phys 219, 943-975 (2006)

11. Golovitchev, VI., Nordin, N., Jarnicki, R., Chomiak, J.: 3D diesel spray simulation using a new detailed chemistry turbulent combustion model. SAE Tech. Paper, 2000-01-1891.

12. Imren, A., Soruşbay, C., Golovitchev, V.I. and Valentino, G.: 'The Full Cycle HD Diesel Engine Simulations Using KIVA-4 Code', SAE Tech. Paper, 2010-01-2234.

13. Konstandopoulos, A.G., Johnson, J.H.: "Wall-Flow Diesel Particulate Filters-Their Pressure Drop and Collection Efficiency", SAE Tech. Paper, 890405.

14. Konstandopoulos, A.G., Kostoglou, M.: Reciprocating flow regeneration of soot filters. Combust Flame 121, 488-500 (2000)

15. Konstandopoulos, A.G., Kostoglou, M., Skaperdas, E., Papaioannou, E., Zarvalis, D., Kladopoulou, E.: "Fundamental Studies of Diesel Particulate Filters: Transient Loading, Regeneration and Aging", SAE Tech. Paper, 2000-01-1016.

16. Kostoglou, M., Housiada, P., Konstandopoulos, A.G.: Multichannel simulation of regeneration in honeycomb monolithic diesel particulate filters. Chem Eng Sci 58, 3273-3283 (2003)

17. Konstandopoulos, A.G., Kostoglou, M., Vlachos, N., Kladopoulou, E.: "Progress in Diesel Particulate Filter Simulation", SAE Tech. Paper, 2005-01-0946.

18. Konstandopoulos, A.G., Kostoglou, M., Lorentzou, S.: "Wall-Scale Reaction Models in Diesel Particulate Filters", SAE Tech. Paper, 2007-01-1130.

19. Konstandopoulos, A.G., Kostoglou, M., Lorentzou, S., Pagkoura, C., Papaioannou, E., Ohno, K., Ogyu, K., Oya, T.: 
"Soot Oxidation Kinetics in Diesel Particulate Filters", SAE Tech. Paper, 2007-01-1129.

20. Lietti, L., Nova, I., Tronconi, E., Forzatti, P.: Transient kinetic study of the SCR-DeNOx reaction. Catal Today 45, 85-92 (1998)

21. Troconi, E., Cavanna, A., Forzatti, P.: Unsteady analysis of NO reduction over selective catalytic reduction-DeNOx monolith catalysts. Ind Eng Chem Res 37, 2341-2349 (1998)

22. Dubien, C., Schweich, D., Mabilon, G., Martin, B., Prigent, M.: Three-way catalytic converter modeling: fast- and slow-oxidizing hydrocarbons, inhibiting species, and steam-reforming reaction. Chem Eng Sci 53(3), 471-481 (1998) 